Materials Sciences Division, Lawrence Berkeley National Laboratory, and

Department of Materials Science and Engineering,

University of California at Berkeley

\title{
FRACTURE, AGING AND DISEASE IN BONE
}

J. W. Ager III ${ }^{1}$, G. Balooch ${ }^{1,2}$ and R. O. Ritchie B, $^{1, *}$

${ }^{1}$ Materials Sciences Division, Lawrence Berkeley National Laboratory, Berkeley, CA 94720

${ }^{2}$ Department of Preventive and Restorative Dental Sciences

University of California, San Francisco, CA 94143

${ }^{3}$ Department of Materials Science and Engineering, University of California, Berkeley, CA 94720

* Corresponding author:

Department of Materials Science and Engineering, 216 Hearst Memorial Mining Building, University of California, Berkeley, CA 94720-1760

Tel: (510) 486-5798; Fax: (510) 486-4881

E-mail address: RORitchie@lbl.gov (R. O. Ritchie)

submitted February 2006

invited paper for August 2006 focus issue of Journal of Materials Research, "Mechanics of Biological and Biomimetic Materials at Small Length-Scales."

This work was supported by the Director, Office of Science, Office of Basic Energy Science, Division of Materials Sciences and Engineering, Department of Energy and the Laboratory Directed Research and Development Program of Lawrence Berkeley National Laboratory (for GB) under contract No. DE-AC02-05CH11231. 


\section{Fracture, aging and disease in bone}

J. W. Ager III' ${ }^{\mathrm{a}}$, G. Balooch ${ }^{\mathrm{a}, \mathrm{b}}$ and R. O. Ritchie ${ }^{\mathrm{a}, \mathrm{c} *}$

a Materials Sciences Division, Lawrence Berkeley National Laboratory, Berkeley, CA 94720

${ }^{\mathrm{b}}$ Department of Preventive \& Restorative Dental Sciences, University of California, San Francisco, CA 94143

${ }^{\mathrm{c}}$ Department of Materials Science and Engineering, University of California, Berkeley, CA 94720

From a public health perspective, developing a detailed mechanistic understanding of the well-known increase in fracture risk of human bone with age is essential. This also represents a challenge from materials science and fracture mechanics viewpoints. Bone has a complex, hierarchical structure with characteristic features ranging from nanometer to macroscopic dimensions; it is therefore significantly more complex than most engineering materials. Nevertheless, by examining the micro-/nano-structural changes accompanying the process of aging using appropriate multiscale experimental methods and relating them to fracture mechanics data, it is possible to obtain a quantitative picture of how bone resists fracture. As human cortical bone exhibits rising ex vivo crack-growth resistance with crack extension, its fracture toughness must be evaluated in terms of resistance-curve (R-curve) behavior. While the crack initiation toughness declines with age, the more striking finding is that the crack-growth toughness declines even more significantly and is essentially absent in bone from donors exceeding 85 years in age. To explain such an age-induced deterioration in the toughness of bone, we evaluate its fracture properties at multiple length scales, specifically at the molecular and nano dimensions using pico-force atomic-force microscopy, nanoindentation and vibrational spectroscopies, at the microscale using electron microscopy and hard/soft x-ray computed tomography, and at the macroscale using R-curve measurements. We show that the reduction in crackgrowth toughness is associated primarily with a degradation in the degree of extrinsic toughening, in particular involving crack bridging, and that this occurs at relatively coarse size-scales in the range of tens to hundreds of micrometers. Finally, we briefly describe how specific clinical treatments, e.g., with steroid hormones to treat various inflammatory conditions, can prematurely damage bone, thereby reducing its fracture resistance, whereas regulating the level of the cytokine TGF- $\beta$ can offer significant improvements in the stiffness, strength and toughness of bone, and as such may be considered as a therapeutic target to treat increased bone fragility induced by aging, drugs, and disease.

\footnotetext{
*Corresponding author: tel: (510) 486-5798; fax: (510) 486-4881
}

E-mail address: RORitchie@lbl.gov (R. O. Ritchie) 


\section{INTRODUCTION}

The structural integrity of mineralized tissues such as human bone and teeth is clearly of particular clinical importance, especially in the case of bone which forms the body's protective load-bearing skeletal framework. Bone is unique when compared to structural engineering materials due to its well known capacity for self-repair and adaptation to changes in mechanical usage patterns. Unfortunately, aging and disease are known to increase the susceptibility of bone fracture, which in the case of the very elderly can lead to significant mortality [1]. Although bone mineral density (BMD) has been routinely used by clinicians as a predictor of fracture risk, particularly for the elderly, there is mounting evidence that this measure of bone quantity is not adequate as the sole predictor of bone fracture, and other factors pertaining principally to bone quality must be considered [2,3]. For example, Hui et al. [4] reported that while BMD was a good predictor of forearm fracture, age was a better predictor of hip fracture, suggesting that these two factors have independent effects; similarly, Aspray et al. [5] concluded that while the bone mineral content (BMC) of rural Gambian women is 10-40\% lower than that of European women of similar age, height, and weight, osteoporosic fractures are rare. Both these studies strongly challenge the concept of bone density as the primary determinant of fracture risk. In addition, BMD has been relied upon to assess the therapeutic benefits of antiresorptive agents in treating osteoporosis, but this may be incomplete as well.

The importance of developing a more complete understanding of fracture risk factors is thus evident. Numerous studies have established that there is a significant deterioration in the toughness of bone with age (e.g., $[6,7,8,9,10])$; nevertheless, a mechanistic framework for describing how the microstructure affects the failure of bone is still lacking. What is needed is an understanding of (i) how aging, disease or therapeutic treatment can affect the structure of bone, defined broadly from nano- through micro- to macro-scopic size-scales, and (ii) how this specifically affects the mechanisms responsible for the deformation and fracture of bone.

Bone has a complex hierarchical structure, as illustrated schematically in Fig. 1, so to develop this understanding, it is necessary to examine the bone-matrix structure and how this affects the mechanistic aspects of damage and fracture over multiple (nano to macro) 
dimensions [11,12]. We first describe the characteristic features of the bone-matrix structure.

\section{STRUCTURE OF BONE}

The basic nanostructural building blocks of all mineralized tissues in the human body, including bone, are an organic matrix of roughly $90 \%$ collagen and mineral phase consisting of calcium phosphate-based apatite mineral. These units are organized into a hierarchy of structures ranging in dimension from molecular to the macroscopic sizescales, and accordingly are far more complex than traditional engineering materials (Fig. $1)$.

Type-I collagen typically comprises $\sim 90 \%$ of the organic matrix of human bone, with a structure that is also hierarchical in nature. Specifically, the collagen molecule comprises a triple helix of peptide chains, specifically two $\alpha_{1}$ chains and one $\alpha_{2}$ chain, each of which are $\sim 1000$ residues long. The molecules are staggered by $67 \mathrm{~nm}$ and covalently crosslinked between lysine residues, the intra- and intermolecular cross-links providing for the tensile strength $[13,14]$. They self-assemble into thin $(10-300 \mathrm{~nm}$ in diameter) collagen fibrils and are impregnated with inorganic carbonated apatite nanocrystals (tens of $\mathrm{nm}$ in length and width, 2-3 $\mathrm{nm}$ in thickness). The fibrils are then aggregated into larger fibers that are micrometers in diameter [15]. At the macrostructural level, bone is distinguished into cortical (compact) and cancellous (trabecular) bone; most long bones are composed of a cortical shell with a cancellous interior. In this review, we will concentrate on cortical bone. At microstructural length-scales, cortical bone is organized into 200-300 $\mu \mathrm{m}$ diameter secondary osteons [16], which are composed of large vascular channels called Haversian canals (50-90 $\mu \mathrm{m}$ diameter) surrounded by circumferential lamellar rings (3-7 $\mu \mathrm{m}$ thick), with so-called "cement lines" at the outer boundary; these secondary osteons are the end result of the remodeling process that repairs damage in vivo. On average, the organic/mineral ratio in human cortical bone is roughly $1: 1$ by volume and $1: 3$ by weight [15]. In addition to its hierarchical complexity, the composition and the structure of bone varies with factors such as skeletal site, age, sex, physiological function and mechanical loading, making bone a very heterogeneous structure, with the need for vascularization adding to the complexity of the tissue. 
One critical question in the understanding of fracture risk in bone is discerning which of the characteristic dimensions in this hierarchical structure is most important in controlling the fracture properties of bone. We believe that specific toughening mechanisms in bone actually exist over most of these dimensions; however, it is our contention that structure at the scale of hundreds of micrometers, i.e., at the level of the Haversian osteons, is most critical to controlling the fracture toughness [17]. This is not to say that molecular and nanostructure is unimportant; rather it is simply the recognition that fracture invariably involves collective phenomena which occur over dimensions far larger than atomistic or molecular size-scales. In this respect, bone is no exception.

Accordingly, in this paper we attempt to characterize structure, damage and fracture properties in bone, as influenced by aging, disease and clinical therapy, using a multitude of techniques pertaining to this range of dimensions. These will include measurements at the molecular and nano scales using pico-force atomic-force microscopy (AFM), nanoindentation and vibrational spectroscopies, at the microscale using electron microscopy and hard/soft x-ray computed tomography, and at the macroscale using fracture mechanics and fatigue testing. We begin by examining the mechanisms by which bone derives its resistance to fracture.

\section{ORIGINS OF TOUGHNESS IN BONE}

\section{Macroscopic quantification}

Whereas the "strength" of a component such as a bone is often thought of as a measure of its fracture resistance, this is actually not the most appropriate descriptor as it takes no account of the inevitable presence of flaws (i.e., cracks) in the material which are known to have a significant effect on fracture. The same can be said for measurements of the "work of fracture", determined from the area under the load/displacement curve in such a test. The key to understanding whether a component will break or not is that it depends not only on the level of applied stress but also on the presence of cracks (which may have been created during use). This is particularly relevant to bone as an increasing volume fraction of microcracks ("micro-damage") is known to form as bone ages. Fracture mechanics provides a viable method to quantify the relationships between the stresses and strains applied to a body, the crack or flaw sizes within it, and the resistance to fracture of the 
underlying material. Coupled with an examination of the mechanisms of fracture and their relation to the nano/microstructure, it provides for a framework for understanding the failure of materials under a variety of loading conditions (e.g., tension, bending, compression, multiaxial loading, cyclic fatigue, etc.), and as such is used extensively to quantify the onset of cracking in traditional engineering.

In general, significant effort has been made over the past ten years or so to elucidate how bone is toughened. There is now a large body of results in the literature involving determinations of the fracture toughness of cortical bone using the linear-elastic fracture mechanics (LEFM) approach. This has for the large part involved single-parameter characterization of the toughness using either the critical value of the mode I linear-elastic stress intensity, $\left.K_{\text {Ic }}[18,19,20,21,22,23]\right)$, or the related strain-energy release rate, $G_{\mathrm{c} .}{ }^{1} \quad$ In terms of $K_{\text {Ic }}$, toughness values in cortical bone range from 2 to $7 \mathrm{MPa} \sqrt{\mathrm{m}}$, with the fracture toughness, in human humeri for example, typically being up to twice as high in the transverse orientation compared to the longitudinal (medial-lateral and proximal-distal) orientations.

Whereas such a fracture mechanics approach represents a significant improvement over measurements of toughness involving parameters such as the work of fracture, there are still problems with this simple single-parameter characterization when applied to bone.

The first of these is that crack propagation in general represents a mutual competition between two classes of mechanisms: intrinsic damage mechanisms that operate ahead of the crack tip and act to promote crack advance, and extrinsic toughening mechanisms that principally operate in the wake of the crack tip and act to impede crack advance by "shielding" the crack from the full applied driving force $[24,25,26]$. Toughening can thus be achieved intrinsically by enhancing the materials resistance to microstructural damage, or extrinsically by promoting crack-tip shielding. Whereas intrinsic mechanisms primarily govern the crack-initiation toughness, extrinsic mechanisms operate behind the crack tip

\footnotetext{
${ }^{1}$ The stress intensity $K_{\mathrm{i}}$ can be defined for three modes of loading: i = I (mode I tensile-opening), II (mode II shear) and III (mode III anti-plane shear). For each of these modes, a corresponding fracture toughness, $K_{\mathrm{ic}}$, may be defined as the critical value of $K_{\mathrm{i}}$ at fracture instability, i.e., when $K_{\mathrm{i}}=Y \sigma_{\mathrm{app}}(\pi a)^{1 / 2}=K_{\mathrm{ic}}$, where $\sigma_{\mathrm{app}}$ is the applied stress, $a$ is the crack length, and $Y$ is a function (of order unity) of crack size and geometry. Alternatively, the toughness can be expressed as a critical value of the strain-energy release rate, $G_{\mathrm{c}}$, defined as the change in potential energy per unit increase in crack area. For an isotropic material, $G_{\mathrm{c}}=K_{\mathrm{Ic}}{ }^{2} / E^{\prime}+K_{\mathrm{IIc}}{ }^{2} / E^{\prime}+K_{\mathrm{IIIc}}{ }^{2} / 2 \mu$, where $E^{\prime}=E$ in plane stress and $E^{\prime}=E /\left(1-\nu^{2}\right)$ in plane stress with $E$ as Young's modulus and $v$ as Poisson's ratio, and $\mu$ is the engineering shear modulus.
} 
along the crack flank and govern the crack-growth toughness. As the latter effect is dependent on the size of the crack, the presence of significant extrinsic toughening results in rising crack-resistance (or R-curve) behavior, where the value of $K$ or $G$ to "drive" a crack rises with crack extension. We will show that akin to many ceramic materials, toughening in cortical bone is predominantly extrinsic, and is associated with shielding mechanisms such as crack deflection and bridging. Since this necessitates an R-curve evaluation, single-value characterizations of the toughness are generally insufficient. Despite this, R-curves have only been utilized in only relatively few studies $[10,17,27,28]$ to characterize human bone fracture.

A second problem pertains to the fact that, as discussed below, such shielding in bone is due primarily to crack bridging and can extend over quite large dimensions, approaching hundreds of micrometers to a few millimeters. Since such "process zones" are not necessarily small compared to the macroscopic size of the bone, a simple single-parameter LEFM characterization using $K_{\text {Ic }}$ can be problematic as the resulting toughness value will likely be size- and geometry-dependent. This problem can be satisfactorily addressed using cohesive-zone modeling approaches [29], but is beyond the scope of the present paper. As we are focusing on mechanisms in the present work, we will use a simple Rcurve approach to provide a macroscopic quantification of the toughness of bone.

\section{Mechanistic considerations}

Bone principally derives its resistance to fracture from extrinsic phenomena. Mechanistically, the toughening can arise from several sources often acting in concert, with their relative contribution typically depending on such factors as orientation and the size-scale. Several salient toughening mechanisms have been identified for human cortical bone, including (in decreasing order of importance) macroscopic crack deflection, crack bridging and constrained microcracking [30]. Essentially all these mechanisms result from the nature of the crack path, the over-riding feature being that certain features in the microstructure provide microstructurally “weak" or preferred paths for cracking; in bone, these are invariably the cement lines, which are the interfaces between the bone matrix and osteon structures. There are several implications of this which are critical for the toughness of cortical bone. 
First, since the cement lines are oriented nominally along the longitudinal axis of the bone, preferred cracking paths will be tend to be along this direction. This can lead to the deflection of cracks attempting to propagate in the transverse direction.

Second, cracking in the cement lines can lead to the general formation of microcracks, i.e., microdamage, particularly as bone ages and the osteon density increases with remodeling. Such microcracking may predominate in the region ahead of a growing (macro) crack where the local stresses are highest.

Third, the nature of the coalescence of such microcracks to the growing crack can lead to the formation of uncracked regions along the crack length which act to "bridge" the crack and increase fracture resistance.

Each of the mechanisms is described in more detail below.

Macroscopic crack deflection: For bones subjected to bending forces where the fracture should occur across the bone in the transverse direction, i.e., along a path of maximum tensile stress, the crack will often macroscopically deflect along the longitudinal direction in order to follow a "weaker" path along the cement lines [20,22,23,30], as can be seen for human cortical bone in Fig. 2 [30]. The effect of this deflection, which is often as much as $90^{\circ}$, is to increase the toughness substantially by reducing the local driving force for crack advance. This can be explained by the following fracture mechanics analysis. Assuming for the sake of simplicity that the deflections are in-plane tilts through an angle $\alpha$ to the crack plane, the local mode-I and mode-II stress intensities, $k_{1}$ and $k_{2}$, at the deflected crack tip are given by [31,32]:

$$
\begin{gathered}
k_{1}(\alpha)=c_{11}(\alpha) K_{\mathrm{I}}+c_{12}(\alpha) K_{\mathrm{II}} \text { and } \\
k_{2}(\alpha)=c_{21}(\alpha) K_{\mathrm{I}}+c_{22}(\alpha) K_{\mathrm{II}},
\end{gathered}
$$

where $K_{\mathrm{I}}\left(\sim 5.3 \mathrm{MPa} \sqrt{\mathrm{m}}\right.$, i.e., the fracture toughness of bone) and $K_{\mathrm{II}}(=0)$ are, respectively, the mode I and mode II far-field (applied) stress intensities for a main crack, and the coefficients, $c_{\mathrm{ij}}(\alpha)$, are mathematical functions of the deflection angle, $\alpha\left(\sim 90^{\circ}\right)[31,32]$. The effective stress intensity at the tip of the deflected crack tip, $K_{\mathrm{d}}$, can then be calculated by summing the mode-I and mode-II contributions in terms of the strain-energy release rate, viz.: 


$$
K_{\mathrm{d}}=\left(k_{1}^{2}+k_{2}^{2}\right)^{1 / 2}
$$

which suggests that the value of the stress intensity at the crack tip is reduced locally by $\sim 50 \%$ due to such deflection to $\sim 2.7 \mathrm{MPa} \sqrt{\mathrm{m}}$, as compared to that for an undeflected crack; the applied stress intensity must then be raised by a factor of two to achieve fracture. This quantification of the toughening effect from macroscopic crack deflection for cracks attemping to propagate in the transverse orientation, where the crack must try and cut the osteons, provides the explanation for the observation that the resistance to fracture in this orientation is approximately twice as high as that in the longitudinal orientations.

Crack bridging is a common toughening mechanism in ceramics and composites $[24,25,26]$, which involves regions of unbroken material behind a crack front (e.g., fibers in a composite) holding the crack faces together, thereby sustaining load that would otherwise be used to advance the crack. Such "bridges" reduce the driving force experienced at the tip, and can result from a variety of crack/structure interactions. In bone, two principal bridging mechanisms can be identified, which operate at very different dimensions (Figs. 3, 4).

Uncracked-ligament bridging $^{2}$ is the most potent bridging mechanism in bone where tracts of material, often several hundred micrometers in dimension, comprise the bridges (Fig. 3). This mechanism results from microcracks forming ahead of the main crack tip, primarily at the cement lines, and their imperfect linkage back to the main crack tip (it can also result from non-uniform crack advance giving the appearance in any two-dimensional section of cracking ahead of the main crack tip). Such a configuration of "mother" and "daughter" cracks is shown in Fig. 3a-b. The consequent bridging mechanism provides a marked contribution to the macroscopic fracture toughness of human bone ${ }^{3}[10,17,30]$; moreover, its degradation with aging has been identified as a major reason why the fracture resistance of bone deteriorates in the aged [10,33].

An estimate of the contribution from this mechanism to the toughness of cortical bone in the longitudinal orientation can be seen from the following simple analysis. Theoretical

\footnotetext{
${ }^{2}$ In the context of fracture, "ligament" here refers to any unbroken material i.e., a crack "bridge", of any type, shape, and size, that spans the crack, and not a ligament in the anatomical sense.
} 
estimates of ligament bridging based on a limiting crack-opening approach [34] give this toughness contribution in terms of the area fraction of bridging ligaments, $f_{\mathrm{ul}}$, on the crack plane ( $\sim .45$, from crack path observations), the total length, $l_{\mathrm{ul}}$, of the bridging zone ( 5 $\mathrm{mm})$, and the applied (far-field) stress intensity $\left(K_{\mathrm{I}} \sim 4.5 \mathrm{MPa} \sqrt{\mathrm{m}}\right)$, viz:

$$
K_{\mathrm{br}}=-f_{\mathrm{ul}} K_{\mathrm{I}}\left[\left(1+l_{\mathrm{ul}} / r b\right)^{1 / 2}-1\right] /\left[1-f_{\mathrm{ul}}+f_{\mathrm{ul}}\left(1+l_{\mathrm{ul}} / r b\right)^{1 / 2}\right],
$$

where $r$ is a rotational factor $(0.20-0.47)$ and $b$ is the length of the remaining uncracked region ahead of the crack. Substituting typical values for these parameters, the contribution to the toughness of bone due to this mechanism is of the order of $K_{\mathrm{br}} \sim 1-1.6 \mathrm{MPa} \sqrt{\mathrm{m}}$; these predictions are comparable to those measured experimentally [17].

Collagen fiber bridging (Fig. 4) is another bridging mechanism where individual collagen fibers span the crack [30,35]. Here, the uniform traction Dugdale zone model of Evans and McMeeking [36] can be used to estimate the contribution to the toughness, viz:

$$
K_{\mathrm{b}}^{\mathrm{f}}=2 \sigma_{\mathrm{b}} f_{\mathrm{f}}\left(2 l_{\mathrm{f}} / \pi\right)^{1 / 2},
$$

where $\sigma_{\mathrm{b}}$ is the normal bridging stress on the fibrils (assumed to be $\sim 100 \mathrm{MPa}$ ), $f_{\mathrm{f}}$ is the effective area fraction of the collagen fibrils active on the crack plane $(\sim 0.15)$, and $l_{\mathrm{f}}$ is the bridging zone length $(\sim 10 \mu \mathrm{m})$. This analysis implies a value of $K_{\mathrm{b}}{ }^{\mathrm{f}} \sim 0.08 \mathrm{MPa} \sqrt{\mathrm{m}}$ for the contribution of collagen fiber bridging to the overall bone-matrix toughness. While this is a relatively minor contribution to the overall toughness, collagen fiber bridging represents a toughening mechanism that operates over far smaller dimensions, i.e., in the submicron range, and this may well be important for promoting resistance to the extension of micronscale microcracks, which often grow under the influence of much lower driving forces [35]. Also, it has been reported recently that the angle between the collagen fibril alignment and crack propagation directions can determine which extrinsic toughening mechanism is dominant, suggesting a more fundamental role in toughening than fiber bridging alone [37]. Finally, in addition to collagen fibers, there is some observational

\footnotetext{
${ }^{3}$ Uncracked-ligament bridging also provides a major contribution to the toughness of dentin in teeth, although in this mineralized tissue, the microcracks that form ahead of the main crack tip are initiated at the tubules [68].
} 
evidence that non-collagenous proteins form such small-scale bridges [38], although it is unclear if these bridges actually are effective by carrying any load.

Microcracking (Fig. 5) in bone represents a mechanism of inelastic deformation; however, in terms of resistance to fracture, the formation of microcracks in the damage zone ahead of a crack tip acts to lower the intrinsic toughness. Structural analysis techniques for observing microcracking have been reviewed recently [39]. However, several authors $[27,40,41]$ have suggested that microcracking may extrinsically toughen bone since a zone of microcracks surrounding a crack would be subjected to some degree of dilation. This dilation, if constrained by surrounding rigid material, coupled with the fact that the microcracked region would be of lower modulus, can thus act to shield the crack tip and hence, extrinsically toughen the material $[42,43]$. However, recent work has shown that the contributions solely from this mechanism in bone are relatively minor [44]; indeed, we believe that the only significance that microcracks may have for toughening is that they result in the formation of uncracked-ligament bridges.

These considerations lead us to conclude that toughening in bone is primarily associated with extrinsic toughening mechanisms, most prominently crack deflection and bridging, which result from the interaction of the crack path with the underlying bonematrix structure. The nature and direction of the crack path, as affected by this structure, orientation, the anatomical nature of the bone and, as described below, aging, disease and clinical therapy, is the crucial factor which determines the potency of these mechanisms. Preferred cracking paths appear to be along the cement lines between the osteon structures, which can cause significant toughening by macroscopic crack deflection (for fractures in the transverse orientation) and by uncracked-ligament bridging. The relative contributions of these mechanisms to the overall toughness provides an explanation for the anisotropy of toughness in bone, and (as described below) their progressive degradation with age provides one reason why the risk of fracture is significantly higher in the elderly. 


\section{DETERIORATION IN BONE FROM AGING}

\section{Macroscopic scale: Fracture toughness behavior}

To first quantify how aging may affect the toughness of bone, we examine macroscopic fracture toughness tests on human cortical bone. The sample set for this study was comprised of human cortical bone taken from the humerii of nine cadavers (donor age: 34 to 99 years) [10]. Seventeen $(N=17)$ compact-tension, $\mathrm{C}(\mathrm{T})$, specimens, were tested with samples were divided into three age groups - arbitrarily named Young (age: $34(N=1), 37(N=4)$ and $41(N=2)$ years), Middle-Aged (age: $61(N=1), 69(N=$ 2) and $69(N=2)$ years) and Aged (age: $85(N=1), 85(N=2)$ and $99(N=2)$ years). The samples were all oriented with the starter notch and the nominal crack-growth direction along the proximal-distal direction of the humerus (in the longitudinal-radial plane), i.e., parallel to the long axis of the osteons and hence, long axis of the humerus. The crackinitiation toughness, $K_{\mathrm{o}}$, was obtained by extrapolating a linear fit of the data for each sample to a crack extension of $\Delta a=0$, while the (linear) slope of the R-curve gave a measure of the crack-growth toughness.

The resulting toughness R-curves are shown in Fig. 6, with statistical summaries given in Fig. 7. Statistical analysis (non-parametric Kruskal-Wallis test) indicated that, for the three age groups, variation among group medians was significant $(P<0.05$ and $<0.01$ for the initiation and the growth toughness, respectively). While the initiation toughness decreases by $40 \%$ over six decades from 40 to 100 years, the effect of aging is much more striking on the growth toughness which is essentially eliminated in the Aged group. The decrease in the initiation toughness is consistent with the trend observed in studies that report single-value toughnesses (e.g., [22,45,46,47,48]). However, the value of R-curve measurements [10] is that is that they clearly show that not only the intrinsic resistance to fracture (as reflected by the crack-initiation toughness), but also the resistance to crack propagation (as reflected by the crack-growth toughness) decreases with age (Figs. 6-7). Indeed, the age-related deterioration in the crack-growth toughness appears to be the dominant effect. 


\section{Micrometer to millimeter scale: Osteons and crack bridging}

Reflective of this marked deterioration in the resistance to fracture of human cortical bone with increasing age, there are significant changes in the bone-matrix structure. One important change that is the statistically significant $(P<0.001)$ increase in density of secondary osteons with age; indeed, the osteonal density almost doubles for 35 to 100 year old bone. Regressions of the osteonal density against the crack-initiation and growth toughnesses both show this effect (Fig. 8), and clearly indicate that the significant agerelated reduction in both measures of the toughness $(P<0.01)$ with increase in osteonal density [33].

By examining the surface of cracked specimens with optical and scanning electron microscopy [33], the increase in osteonal density with age can be seen to be accompanied by a decrease in the extent of crack bridging. This is particularly evident from threedimensional x-ray computed tomography (XRT) imaging ${ }^{4}$, which has provided the most quantitative evidence for the role of crack bridging as a toughening mechanism in bone. Shown in Figs. 9a-b are tomographic slices obtained from the Young and Aged groups as a function of distance behind the crack tip. Crack bridging from uncracked ligaments can be seen in both cases, as evidenced by intact regions, often tens of micrometers in size, observed along the crack path (the three-dimensional nature of the bridges can be seen in Fig. 3). However, there are fewer bridges, which are smaller in size, in the Aged sample. Specifically, the bridging-zone fraction remains roughly constant up to the crack tip in the Young sample (Fig. 9c), whereas in the Aged sample, it is initially comparable but then falls nearly to zero within a few millimeters of the crack tip.

Worthy of note here are the large dimensions, of the order of hundreds of micrometers or more, over which the phenomena which influence fracture occur. However, it is interesting to speculate how these toughening mechanisms, specifically crack bridging degrade with age. The correlation of the decay in toughness with an increase in osteonal density with age provides a clue here. As noted above, uncracked-ligament bridges are formed when microcracks open up ahead of the main crack tip, and then temporarily fail to

\footnotetext{
4 XRT was performed at the Stanford Synchrotron Radiation Laboratory (25 keV), Menlo Park, CA, and at the Advanced Light Source (18 keV), Berkeley, CA, with a typical voxel size (equivalent to the spatial resolution) of $\sim 5 \mu \mathrm{m}$.
} 
link perfectly with the main crack. As the microcracks preferentially form at the cement lines, the size of the resulting bridges is comparable with the osteon spacing. In older bone, excessive remodeling leads to a higher density of secondary osteons which necessarily are closer spaced, and the consequences of this are smaller bridges, less toughening and hence an increased risk of fracture.

\section{Sub-micrometer scale: Atomic force microscopy studies}

Aside from these age-related changes in the bone-matrix structure at the micrometer to millimeter scale which directly affect the fracture resistance, other aspects of the structure of bone, at much smaller dimensions, are altered with age. To evaluate these changes at the sub-micrometer scale, the character and mechanical behavior of individual collagen fibers was examined, in partially decalcified bone samples, using pico-force nanoindentation/atomic force microscopy (ARM) [33]. The unloading load-displacement data obtained with the AFM were used to determine the elastic modulus using classical indentation theory [49]. Fig. 10 shows typical AFM images of individual collagen fibers and there respective moduli at specific locations. It is clear that whereas the collagen in the younger bone displayed a very regular structure with well-defined "Hodge-Petruska" banding with ca. $69 \mathrm{~nm}$ periodicity, this was not always the case in older bone where areas with relatively disorganized collagen, often with much lower moduli, were observed. While this current dataset is too small to draw too many definitive conclusions, such deterioration in the collagen with age clearly will also likely affect the fracture resistance; moreover, the changes in collagen banding may explain the trends observed at molecular dimensions in the UV-Raman spectra, as discussed below.

\section{Molecular scale: Raman studies}

At molecular, i.e., ultrastructural, dimensions, vibrational spectroscopy can be used to probe for structural degradation, and in this regard both Fourier transform infrared (FTIR) [50,51] and visible and near-IR Raman spectroscopies [9,52] have been employed. It should be noted, however, that a specific challenge of applying visible Raman spectroscopy to solid biological tissue is fluorescence interference [53]; this has led to the use of near-IR excitation [54,55,56] and highly sophisticated background subtraction and data analysis techniques $[9,57]$ to mitigate this problem. To help resolve this issue, we 
have reported recently the first in situ deep ultraviolet Raman spectroscopy measurements on human cortical bone [58], where the use of $244 \mathrm{~nm}$ excitation both completely eliminates the fluorescence interference and increases the signal strength of some features from the organic (collagen) phase due to resonance effects.

In our studies of bone [58], and also dentin [59], we have found that most of the variation occurs in the spectral region from 1400 to $1800 \mathrm{~cm}^{-1}$, as shown by the data from the Young, Middle-Aged, and Aged cortical bone sample sets in Fig. 11. Spectral features due to both the amide backbone (amide I and II) and resonance-enhanced side chain vibrations (e.g., Y8a tyrosine ring stretching) were observed and are indicated in the figure. Quantitative analysis, performed by using non-linear least-squares fitting to determine the heights of the four overlapping features with the indicated approximate frequencies, specifically $\mathrm{CH}_{2}$ wag $-1460 \mathrm{~cm}^{-1}$, amide II $-1550 \mathrm{~cm}^{-1}$, Y8a - $1620 \mathrm{~cm}^{-1}$, amide I - 1660 $\mathrm{cm}^{-1}$, reveals the somewhat significant trend (Pearson correlation, $P<0.10$ ) suggested by Fig. 11 of an increase in the amide I peak height with increasing age [58]. Our working hypothesis is that this effect is due to broadening of the resonance profile for the amide $\pi \rightarrow \pi^{*}$ transition caused by changes in the intrafibrallar environment of the collagen molecules. It is well established that the density of bone on the macroscopic scale decreases with age due to natural processes and to bone metabolic diseases such as osteoporosis; however, the density of mineral per unit volume of bone, excluding porosities, actually increases [60]. It is possible that the increased bone density is responsible for the age-related changed in the amide I resonance Raman peak height, but clearly more study is required.

Statistical analysis (Pearson correlation) of the Raman and R-curve data obtained from the same samples showed a significant relationship between the amide I peak height and the crack-initiation toughness $(P<0.05)$; the corresponding relationship with the crackgrowth toughness was not significant $(P>0.10)$. We consider this to be further evidence to our notion that the reduction of crack bridging, and hence fracture toughness, in aged bone has its origins primarily at microscopic, as opposed to ultrastructural, length scales. 


\section{Mechanistic summary}

These results show clear evidence of a marked degradation in bone quality, specifically from a significant decrease in the fracture toughness (for both initiating and growing cracks) for human cortical bone between the ages of 34 and 99 years. Such macroscopic changes in fracture resistance can be related to substantial age-related changes in structure over dimensions from molecular to those in the hundreds of micrometers. Whereas there are definitive changes in the collagen environment at molecular levels, and an apparent degradation in collagen fibril structure and corresponding mechanical properties at submicrometer levels, it is the increase in osteonal density at coarser dimensions which we believe has the most significant effect on toughness. The larger number of secondary osteons, which can be caused by increased remodeling with age, can lead to larger numbers of microcracks but to smaller crack bridges; this in turn results in lower toughness and hence to a greater risk of bone fracture in older bone.

\section{DETERIORATION IN BONE FROM DISEASE AND CLINICAL TREATMENT}

Skeletal development and homeostasis are regulated by growth factors and hormones, which regulate cell differentiation, cell function, and matrix deposition. Glucocorticoids, which are steroid hormones widely used for the treatment of inflammatory conditions such as arthritis and dermatitis, have been associated in clinical studies with an increase in the risk of bone fracture, especially in the spinal vertebrae and the femoral head $[61,62,63]$. It is known that glucocorticoids alter bone metabolism in such a way as to decrease bone density and change trabecular bone architecture. However, these changes do not explain the observed increase in fracture risk in patients treated with glucocorticoids. For example, the fracture risk of in patients treated with glucocorticoids is higher than in women with postmenopausal osteoporosis who have lower bone mineral densities $[64,65]$. It is therefore important to assess specific mechanical property changes in bone, in addition to bone mass and architecture, that occur in response to glucocorticoid treatments; in this regard, our recent studies have focused on steroid effects in mouse bone [66].

Specifically, changes in the fifth lumbar vertebral body were assessed for the trabecular bone structure (using microCT and histomorphometry), the elastic modulus of individual lumbar vertebrae trabecula (Elastic Modulus Mapping - EMM), and the mineral-to-matrix 
ratio (Raman micro-spectroscopy) in glucocorticoid-treated mice and placebo-treated controls for comparison to estrogen deficient mice and sham-operated controls. EMM, a modified AFM-based nanoindentation technique that assesses elastic modulus without plastically deforming the tissue, was used to map $256 \times 256$ points of elastic modulus with high spatial resolution $(\sim 15 \mathrm{~nm})$. Using EMM, the average elastic modulus over the entire surface of each trabecula was found to be similar in all the experimental groups; however, localized changes within the trabeculae in areas surrounding the osteocyte lacunae were observed in the glucorticoid-treated mice (Fig. 12a). In particular, the size of the osteocyte lacunae was increased, but more importantly a zone of reduced elastic modulus, concomitant with a "halo" of hypo-mineralized bone (Fig. 12b), was observed around these lacunae. Based on these results, it appears that glucocorticoids may have direct effects on osteocytes resulting in a modification of their microenvironment from localized changes in elastic modulus and bone mineral-to-matrix ratio. Consistent with the fact that steroid treatment is known to increase bone fragility, we anticipate that these local changes in bone-matrix structure will likely lead to reduced toughness levels in glucocorticoidtreated bone. However, it is by no means clear that the mechanism(s) by which steroid treatment degrades bone quality will be similar to those caused by aging, particularly given that the elastic property changes appear to be localized. This subject will be addressed in future work.

Bone architectural properties such as cortical bone thickness and trabecular bone volume and organization are regulated by a variety of cytokines and hormones. A cytokine known to be important in bone formation is Transforming Growth Factor- $\beta$ (TGF- $\beta$ ). The complex biological role of TGF- $\beta$ signaling on osteoblast proliferation and differentiation has been studied in vitro and in vivo. However, a direct connection between of TGF- $\beta$ signaling and the mechanical properties of the bone matrix itself has only recently been discovered [67]. Measurements of the local mechanical properties, matrix composition, and fracture toughness were performed on mice with different levels of TGF- $\beta$ signaling. Compared to wild-type mice, D4 and D5 mice, expressing 16- and 2.5-fold increased levels of active TGF- $\beta$ in bone, showed a reduction in elastic modulus (measured by AFMnanoindentation, Fig. 13(a), bone mineral concentration (assessed by synchrotron x-ray tomography, Fig. 13(b), and fracture toughness (by $\sim 30 \%$ ). In contrast, partial reduction in 
TGF- $\beta$ signaling in transgenic DNT $\beta$ RII mice expressing a dominant negative version of the type II TGF- $\beta$ receptor in osteoblasts had elevated elastic modulus (Fig. 13a), bone mineral concentration (Fig. 13b), and fracture toughness (by $\sim 50 \%$ ). This was also observed in mice with partial reduction in TGF- $\beta$ signaling through heterozygote loss of Smad3, the intracellular target of TGF- $\beta$ signaling in osteoblasts. Such results indicate that TGF- $\beta$ can regulate mechanical properties and mineral concentration of bone matrix, and thereby contributes to the bone's ability to resist fracture; in essence, reduced TGF- $\beta$ signaling increases functional parameters of bone quality.

In view of the fact that most bone disorder drugs today primarily treat the problem of bone quantity, which is now known to be only a relatively small part of the issue of increased fragility of bone with age, these results suggest possible clinical treatments for the more important problem of bone quality. Specifically, a reduction of TGF- $\beta$ signaling should perhaps be considered as a therapeutic target to treat bone disorders. This is particularly pertinent as numerous TGF- $\beta$ inhibitors are currently in preclinical or clinical trials for treatment of cancer metastases.

\section{CONCLUDING REMARKS}

In this review, we have examined in detail toughening mechanisms in bone and then how this resistance to fracture can be degraded by processes of aging, disease and clinical treatments. Our approach can be considered "worst-case" in that we have treated bone as a structural material and not considered that damage can be repaired in vivo through remodeling; we have also not considered the specific role of fatigue loading. However, studies over a wide range of length-scales leads us to believe that whereas bone is toughened at multiple dimensions, it is phenomena at the scale of tens to hundreds of micrometers that dominates its fracture properties. Specifically, microcracking, preferentially at the cement lines of the osteon structures, promotes the two primary toughening mechanisms in bone, namely crack bridging (principally due to uncracked ligaments) and macroscopic crack deflection (for cracks propagating in the transverse orientation). Indeed, similar behavior can be seen in tooth dentin, although the microcracking that promotes the uncracked-ligament bridging is now associated with the 
dentinal tubules at the micrometer scale and macroscopic crack deflection is generally not an issue $[68,69]$.

The effects of aging on the structure and properties of bone can also be identified through nano-/micro-mechanisms at multiple dimensions. Factors such as increased mineralization [9,70], increased microdamage [35,71], lowered collagen quality [47], and increased bone turnover [72] have all been implicated, although a consistent picture of how all this precisely affects the bone-matrix toughness is still uncertain. Again our premise is that although we can directly measure molecular changes in the collagen environment and a deterioration in the nature and properties of individual collagen fibrils at sub-micrometer dimensions, it is phenomena at the tens to hundreds of micrometers that is most pertinent to how aging degrades the toughness. That is, our results show a clear reduction in the fraction and size of crack bridges in older bone, which we believe is associated with a higher density of (secondary) osteons from excessive remodeling [10,33].

Our studies on disease and clinical treatment in their effect on the structure and toughness of bone are still in their infancy; however, the challenge is again is to identify and quantify the specific fracture mechanisms affected by each biological process in light of changes that occur in the bone-matrix nano-/micro-structure. It is through such a multidimensional mechanistic approach, which combines biology, materials science and fracture mechanics, that a clearer understanding of what toughens and embrittles bone can be achieved. We believe that such information can be used a basis for the design of improved drug therapies to reduce the risk of bone fracture in the elderly and in other at-risk populations.

\section{ACKNOWLEDGMENTS}

This work was supported by the Director, Office of Science, Office of Basic Energy Science, Division of Materials Sciences and Engineering, Department of Energy (JWA, ROR) and the Laboratory Directed Research and Development Program of Lawrence Berkeley National Laboratory (for GB) under contract No. DE-AC02-05CH11231. We acknowledge the support of x-ray wiggler beamline (BL 10-2) at the Stanford Synchrotron Radiation Laboratory (SSRL), supported by Department of Energy, contract No. DEAC03-76SF00515, and the dedicated tomography beamline (BL 8.3.2) at the Advanced 
Light Source (ALS), supported by the Department of Energy (BES) under contract No. DE-AC03-76SF00098. Particular thanks are due to the many individuals who were involved in the work reviewed in this paper, including Drs. R. K. Nalla, J. J. Kruzic, J. H. Kinney, A. E. Porter, T. Alliston, M. Balooch, A. P. Tomsia, and Profs. N. E. Lane and R. Derynck. We also thank Drs. C. Puttlitz and Z. Xu for supplying the human cortical bone.

\section{REFERENCES}

1. A. G. Jennings and P. de Boer: Should we operate on nonagenarians with hip fractures? Injury 30, 169 (1999).

2. R. Heaney: Is the paradigm shifting? Bone 33, 457 (2003).

3. P. D. Miller, M. C. Hochberg, L. E. Wehren, P. D. Ross, and R.D. Wasnich: How useful are measures of BMD and bone turnover? Curr Med Res Opin., 21, 545 (2005).

4. S. L. Hui, C. W. Slemenda, and C. C. Johnston: Age and bone mass as predictors of fracture in a prospective study. J. Clin. Invest. 81, 1804 (1988).

5. T. J. Aspray, A. Prentice, T. J. Cole, Y. Sawo, J. Reeve, and R. M. Francis: Low bone mineral content is common but osteoporotic fractures are rare in elderly rural Gambian women. J. Bone Miner. Res. 11, 1019 (1996).

6. A. Burstein, D. Reilly, and M. Martens: Aging of bone tissue: mechanical properties. J. Bone Joint Surg. 58A, 82 (1976).

7. P. Zioupos and J. D. Currey: Changes in the stiffness, strength, and toughness of human cortical bone with age - An underexplored frontier. Bone 22, 57 (1998).

8. Y. N. Yeni and T. L. Norman: Fracture toughness of human femoral neck: effect of microstructure, composition, and age. Bone 26, 499 (2000).

9. O. Akkus, F. Adar, and M. B. Schaffler: Age-related changes in physicochemical properties of mineral crystals are related to impaired mechanical function of cortical bone. Bone 34, 443 (2004).

10. R. K. Nalla, J. J. Kruzic, J. H. Kinney, and R. O. Ritchie: Effect of aging on the toughness of human cortical bone: evaluation by R-curves. Bone 35, 1240 (2004).

11. J.-Y. Rho, L. Kuhn-Spearing, and P. Zioupos: Mechanical properties and the hierarchical structure of bone. Med. Eng. Phys. 20, 92 (1998).

12. S. Weiner and H. D. Wagner, The material bone: Structure-mechanical function relations Annu. Rev. Mater. Sci. 28, 271 (1998).

13. D. R. Eyre, M. A. Paz, and P. M. Gallop: Cross-linking in collagen and elastin. Annual Rev Biochem. 53, 717 (1984).

14. L. Knott and A. J. Bailey: Collagen cross-links in mineralizing tissues: A review of their chemistry, function, and clinical relevance. Bone 22, 181 (1998). 
15. A. Veis: Collagen fibrallar structure in mineralized and nonmineralized tissues. Current Opinion in Sol. State Mat. Sci. 2, 370 (1997).

16. J. D. Currey: Osteons in biomechanical literature, J. Biomech. 15, 717 (1982).

17. R. K. Nalla, J. J. Kruzic, J. H. Kinney, and R. O. Ritchie: Mechanistic aspects of fracture and R-curve behavior in human cortical bone. Biomaterials 26, 217 (2005).

18. W. Bonfield: Advances in the fracture mechanics of cortical bone. J. Biomech. 20, 1071 (1987).

19. T. L. Norman, D. Vashishth, and D. B. Burr. Fracture toughness of human bone under tension. J. Biomech. 28, 309 (1995).

20. X. D. Wang, N. S. Masilamani, J. D. Mabrey, M. E. Alder, and C. M. Agrawal: Changes in the fracture toughness of bone may not be reflected in its mineral density, porosity, and tensile properties - Effects of sampling sites and crack orientations. Bone 23, 67 (1998).

21. C. U. Brown, Y. N. Yeni, and T. L. Norman. Fracture toughness is dependent on bone location- A study of the femoral neck, femoral shaft, and the tibial shaft. J. Biomed. Mater. Res. 49, 380 (2000).

22. J. B. Phelps, G. B. Hubbard, X. Wang, and C. M. Agrawal. Microstructural heterogeneity and the fracture toughness of bone. J. Biomed. Mater. Res. 51, 735 (2000).

23. P. Lucksanambool, W. A. J. Higgs, R. J. E. D. Higgs, and M. W. Swain. Fracture toughness of bovine bone: Influence of orientation and storage media. Biomaterials 22, 3127 (2001).

24. R. O. Ritchie: Mechanisms of fatigue crack propagation in metals, ceramics and composites: role of crack tip shielding. Mater. Sci. Eng. 103, 15 (1988).

25. A. G. Evans: Perspective on the development of high-toughness ceramics. J. Am. Ceramic Soc. 73, 187 (1990).

26. R. O. Ritchie: Mechanisms of fatigue-crack propagation in ductile and brittle solids. Int. J. Fracture 100, 55 (1999).

27. D. Vashishth, J. C. Behiri, and W. Bonfield: Crack growth resistance in cortical bone: concept of microcrack toughening. J. Biomech. 30, 763 (1997).

28. P.-C. Wu and D. Vashishth: Age-related changes in cortical bone toughness: initiation vs. propagation., in Proceedings of the $2^{\text {nd }}$ Joint EMBS/BMES Conference Vol. 1, (IEEE, 2002), p. 425

29. Q. D. Yang, B. N. Cox, R. K. Nalla, and R. O. Ritchie: Fracture length scales in human cortical bone: The necessity of nonlinear fracture models. Biomaterials 27, 2095 (2006).

30. R. K. Nalla, J. H. Kinney, and R. O. Ritchie: Mechanistic fracture criteria for the failure of human cortical bone. Nature Materials 2, 164 (2003).

31. B.A. Bilby, G. E. Cardew, and I. C. Howard: Stress intensity factors at the tips of kinked and forked cracks in Fracture 1977, vol. 3. (Pergamon Press, Oxford. 1978), pp. 197-200.

32. B. Cotterell and J. R. Rice: Slightly curved or kinked cracks. Int J Fract 16, 155 (1980). 
33. R. K. Nalla. J. J. Kruzic, J. H. Kinney, M. Balooch, J. W. Ager, III, and R. O. Ritchie: Role of microstructure in the aging-related deterioration of the toughness of human cortical bone. Mater. Sci. Eng. C, 26, (2006), in press.

34. J.-K. Shang and R. O. Ritchie: Crack bridging by uncracked ligaments during fatiguecrack growth in SiC-reinforced aluminum-alloy composites. Metall. Trans. A 20A, 897 (1989).

35. Y. N. Yeni and D. P. Fyhrie: Fatigue damage-fracture mechanics interaction in cortical bone. Bone 30, 509 (2002).

36. A. G. Evans and R. M. McMeeking: On the toughening of ceramics by strong reinforcements. Acta. Metall. 34, 2435 (1986).

37. H. Peterlik, P. Roschger,K. Klaushofer, and P. Fratzl: From brittle to ductile fracture of bone. Nature Materials 5, 53 (2006).

38. G. E. Fantner, T. Hassenkam, J. H. Kindt, J. C. Weaver, H. Birkedal, L. Pechenik, J. A. Cutroni, G. A. G. Cidade, G. D. Stucky, D. E. Morse, and P. K. Hansma: Sacrificial bonds and hidden length dissipate energy as mineralized fibrils separate during bone fracture. Nature Materials 4, 612 (2005).

39. N. D. Sahar, S.-I. Hong, and D. K. Koln: Micro- and nano-structural analysis of damage in bone. Micron. 36, 617 (2005).

40. D. Vashishth, K. E. Tanner, and W. Bonfield: Contribution, development and morphology of microcracking in cortical bone during crack propagation. .J Biomech. 331169 (2000).

41. D. Vashishth, K. E. Tanner, and W. Bonfield: Experimental validation of a microcracking-based toughening mechanism for cortical bone. J. Biomech 36121 (2003).

42. A. G. Evans and K. T. Faber: Crack-growth resistance of microcracking brittle materials. J. Am. Ceram. Soc. 67, 255 (1984).

43. J. W. Hutchinson: Crack tip shielding by micro-cracking in brittle solids. Acta Metall. 35, 1605 (1987).

44. R. K. Nalla, J. J. Kruzic, and R. O. Ritchie: On the origin of the toughness of mineralized tissue: Microcracking or crack bridging. Bone 34, 790 (2004).

45. C. U. Brown, Y. N. Yeni, and T. L. Norman: Fracture toughness is dependent on bone location--a study of the femoral neck, femoral shaft, and the tibial shaft. J. Biomed. Mater. Res. 49, 380 (2000).

46. P. Zioupos, J. D. Currey, and A. J. Hamer: The role of collagen in the declining mechanical properties of aging human cortical bone. J. Biomed. Mater. Res. 2, 108 (1999).

47. X. Wang, X. Shen, X. Li, and C. M. Agrawal: Age-related changes in the collagen network and toughness of bone. Bone 31, 1 (2002).

48. J. D. Currey, K. Brear, and P. Zioupos: The effects of ageing and changes in mineral content in degrading the toughness of human femora. J. Biomech. 29, 257 (1996).

49. G. M. Pharr, W. C. Oliver, and F. R. Brotzen: On the generality of the relationship between contact stiffness, contact area, and elastic modulus during indentation, $J$. Mater. Res. 7, 613 (1992). 
50. E. P. Paschalis, E. Shane, G. Lyritis, G. Skarantavos, R. Mendelsohn, and A.L. Boskey: Bone fragility and collagen cross-links. J. Bone Miner. Res. 19, 2000 (2004).

51. A. Boskey and R. Mendelsohn: Infrared analysis of bone in health and disease. $J$. Biomed. Optics. 10, 031102 (2005).

52. A. Carden and M. D. Morris: Application of vibrational spectroscopy to the study of mineralized tissues (review). J Biomed Opt. 5, 259 (2000).

53. J. J. Freeman and M. J. Silva: Separation of the Raman spectral signatures of bioapatite and collagen in compact mouse bone bleached with hydrogen peroxide. Appl. Spectros. 56, 770 (2002).

54. J. A. Timlin., A. Carden, and M. D. Morris, J. F. Bonadio, C. E. Hoffler II, K. M. Kozloff, and S. A. Goldstein: Spatial distribution of phosphate species in mature and newly generated mammalian bone by hyperspectral Raman imaging. J. Biomed. Optics 4, 8 (1999).

55. C. G. Kontoyannis and N. V. Vagenas: FT-Raman spectroscopy: A tool for monitoring the demineralization of bones. Appl. Spectros. 54, 1605 (2000).

56. R. J. Lakshmi, M. Alexander, J. Kurien, K. K. Mahato, and V. B. Kartha: Osteoradionecrosis (ORN) of the mandible: A laser Raman spectroscopic study. Appl. Spectros. 57, 1100 (2003).

57. A. Carden, R. M. Rajachar, M. D. Morris, and D. H. Kohn: Ultrastructural changes accompanying the mechanical deformation of bone tissue: A Raman imaging study. Calcif Tissue Int. 72, 166 (2003).

58. J. W. Ager III, R. K. Nalla, K. L. Breeden, and R. O. Ritchie: Deep-ultraviolet Raman spectroscopy study of the effect of aging on human cortical bone J. Biomed. Opt. 10, 034012 (2005).

59. R. K. Nalla, M. Balooch, J. W. Ager III, J. J. Kruzic, J. H. Kinney, and R. O. Ritchie: Effects of polar solvents on the fracture resistance of dentin: role of water hydration, Acta Biomater. 1, 31 (2005).

60. G. M. Kiebzak: Age-related bone changes. Exp Gerontol. 26, 171 (1991).

61. C. Cooper, C. Coupland, and M. Mitchell: Rheumatoid arthritis, corticosteroid therapy, and hip fracture. Ann.Rheum Dis. 54, 49 (1995).

62. N. E. Lane: An update on glucocorticoid-induced osteoporosis. Rheumatic Disease Clinics of North America, guest ed. N. E. Lane, 27, 235 (2001).

63. K. G. Saag: Glucocorticoid-induced osteoporosis. Endocrinol Metab. Clin. North Am, 32, 135 (2003).

64. T. P. Van Staa, H.S. Leufkens, and C. Cooper: The epidemiology of cortico-steroid osteoporosis. A meta-analysis. Osteoporos Int. 13, 777 (2002).

65. T. P. Van Staa, R. F. Laan, I. P. Barton, S. Cohen, D. M. Reid, and C. Cooper: Bone density threshold and other predictors of vertebral fractures in patients receiving oral Glucocorticoid therapy. Arthritis \& Rheum. 48, 3224 (2003).

66. N. E. Lane, W. Yao, M. Balooch, R. K. Nalla, G. Balooch, S. Habelitz, J. H. Kinney, and L. Bonewald: Glucocorticoid treated mice have localized changes in trabecular bone material properties and osteocyte lacunar size that are not observed in placebo treated or estrogen deficient mice. J. Bone Miner. Res. 21 (2006. 
67. G. Balooch, M. Balooch, R. K. Nalla, S. Schilling, E. H. Filvaroff, G. W. Marshall, S. J. Marshall, R. O. Ritchie, R. Derynck, and T. Alliston: TGF- regulates the mechanical properties and composition of bone matrix. Proc. Natl. Acad. Sci. 102, 18813 (2005).

68. J. J. Kruzic, R. K. Nalla, J. H. Kinney, and R. O. Ritchie: Crack blunting, crack bridging and resistance-curve fracture mechanics of dentin: Effect of hydration. Biomaterials, 24, 5209 (2003).

69. J. H. Kinney, R. K. Nalla, J. A. Pople, T. M. Breunig, and R. O. Ritchie: Age-Related Transparent Root Dentin: Mineral Concentration, Crystallite Size, and Mechanical Properties. Biomaterials 26, 3363 (2005).

70. O. Akkus, A. Polyakova-Akkus, F. Adar, and M. B. Schaffler: Aging of microstructural compartments in human compact bone. J. Bone Miner. Res. 18, 1012 (2003).

71. M. B. Schaffler, K. Choi, and C. Milgrom: Aging and matrix microdamage accumulation in human compact bone. Bone 17, 521 (1995)

72. R. W. McCalden, J. A. McGeough, M. B. Barker, C. M. Court-Brown: Age-related changes in the tensile properties of cortical bone. The relative importance of changes in porosity, mineralization, and microstructure. J. Bone Joint Surg. Am. 75, 1193 (1993). 


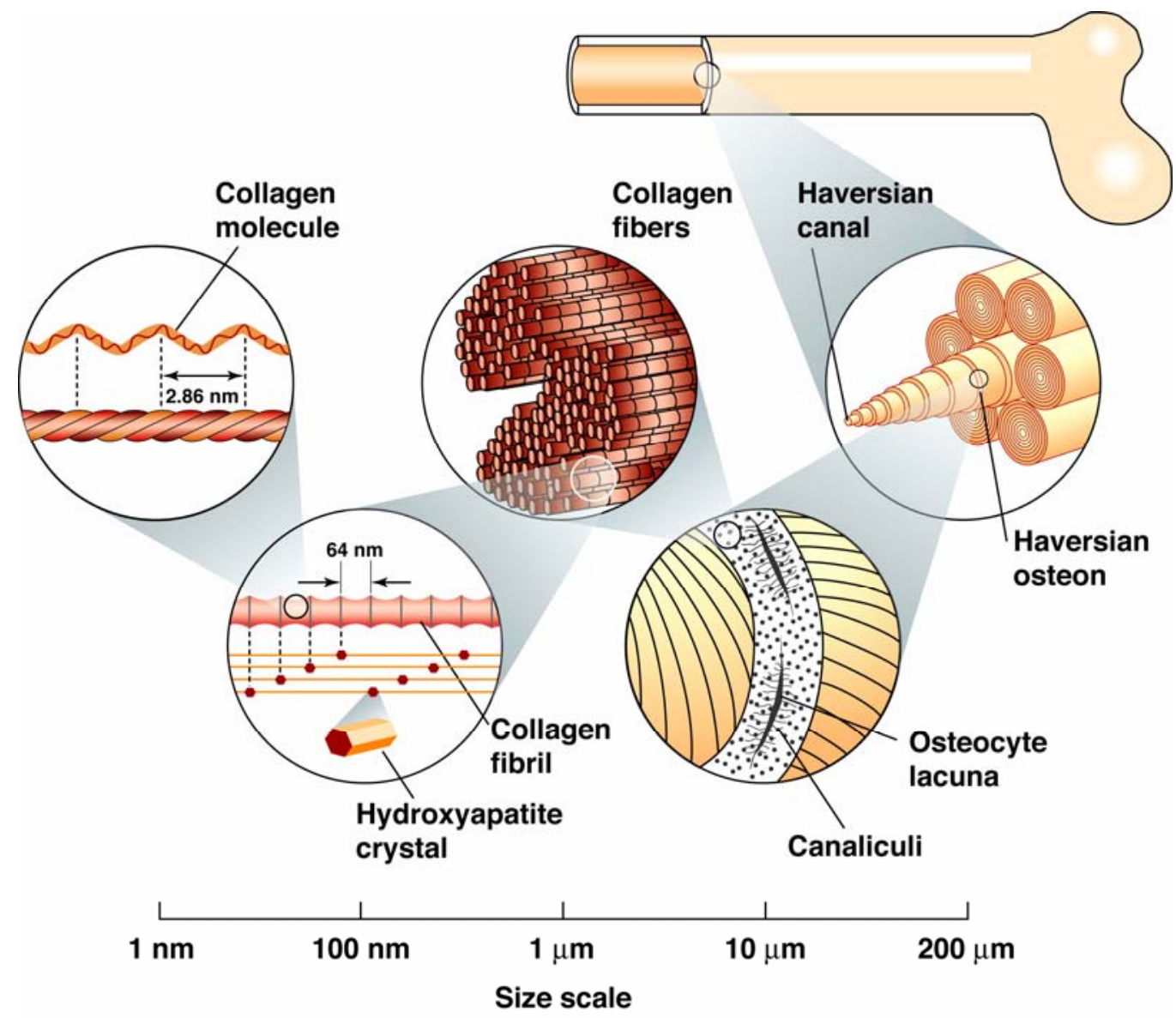

FIG. 1. Schematic illustrating the complex and hierarchical structure of cortical bone [33]. The length scales relevant in our discussion of extrinsic toughening mechanisms range from are tens to hundred of nanometers (diameter of collagen fibrils) to hundreds of micrometers (osteocyte lacuna and osteons). 

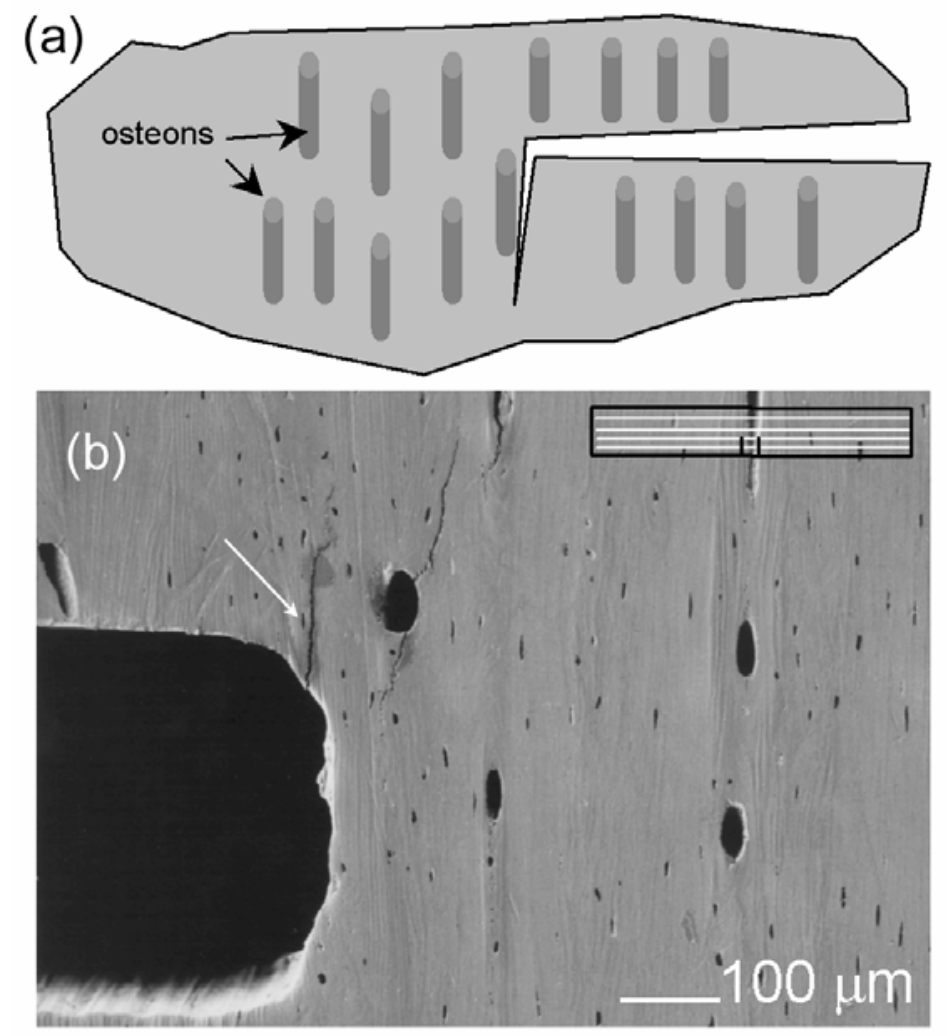

FIG. 2. (a) Schematic depiction of macroscopic crack deflection. For bones subjected to bending forces where the fracture should occur across the bone in the transverse direction, i.e., along a path of maximum tensile stress, the crack will often macroscopically deflect along the longitudinal direction in order to follow a "weaker" path along the cement lines. This is shown in the SEM image in (b); cracking ahead of the notch shows macroscopic crack deflection as the preferred crack path is along the cement lines of the osteons [30]. 
(a)
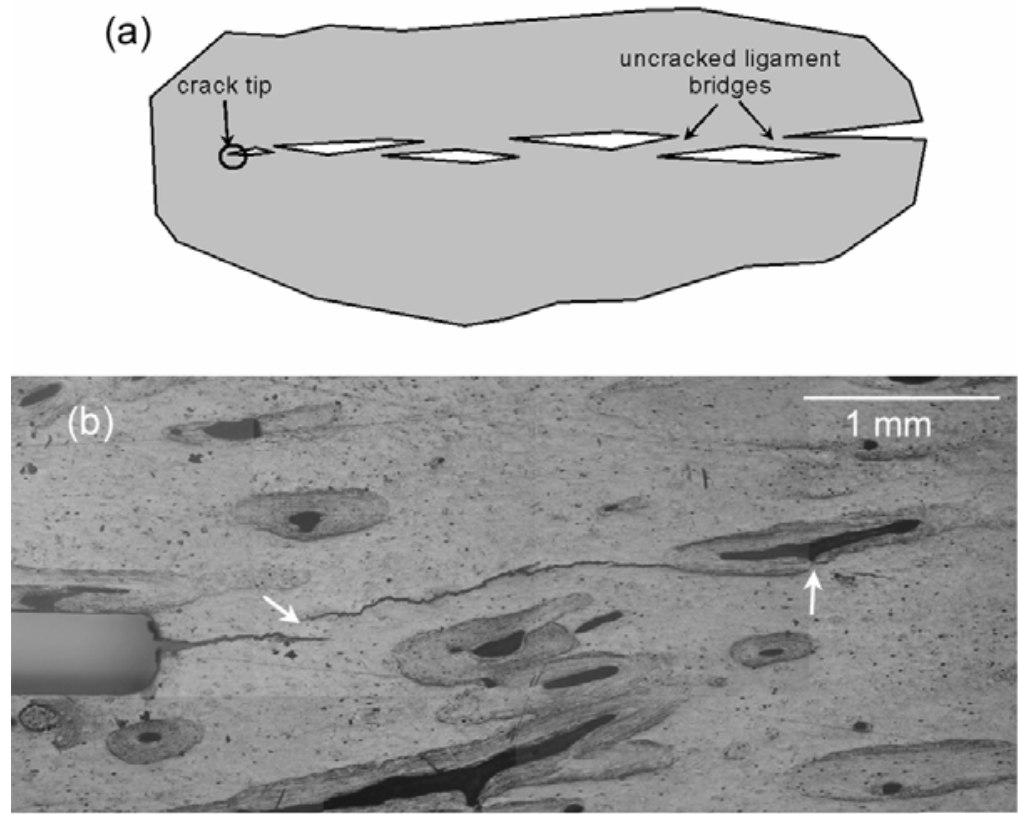

(c)

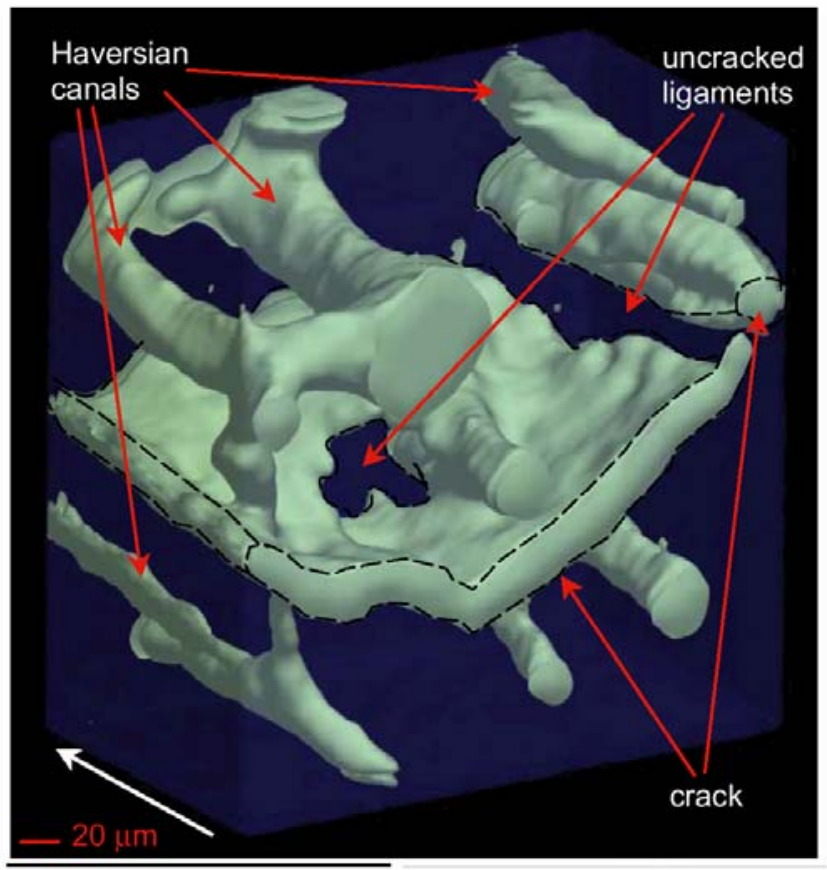

FIG. 3. Uncracked-ligament bridging created by microcracking ahead of the main crack is illustrated in (a) with "mother" and "daughter" cracks. In (b), a typical optical micrograph of stable crack growth in 34-year old human cortical bone, clearly shows the presence of uncracked ligaments on the size scale of tens of microns (indicated by white arrows) in the crack wake. Subsurface crack bridging is shown in three-dimensions in human cortical bone in the x-ray tomographic reconstruction in (c). Uncracked ligaments are indicated, and the white arrow is the direction of nominal crack growth $[17,30]$. 
(a)
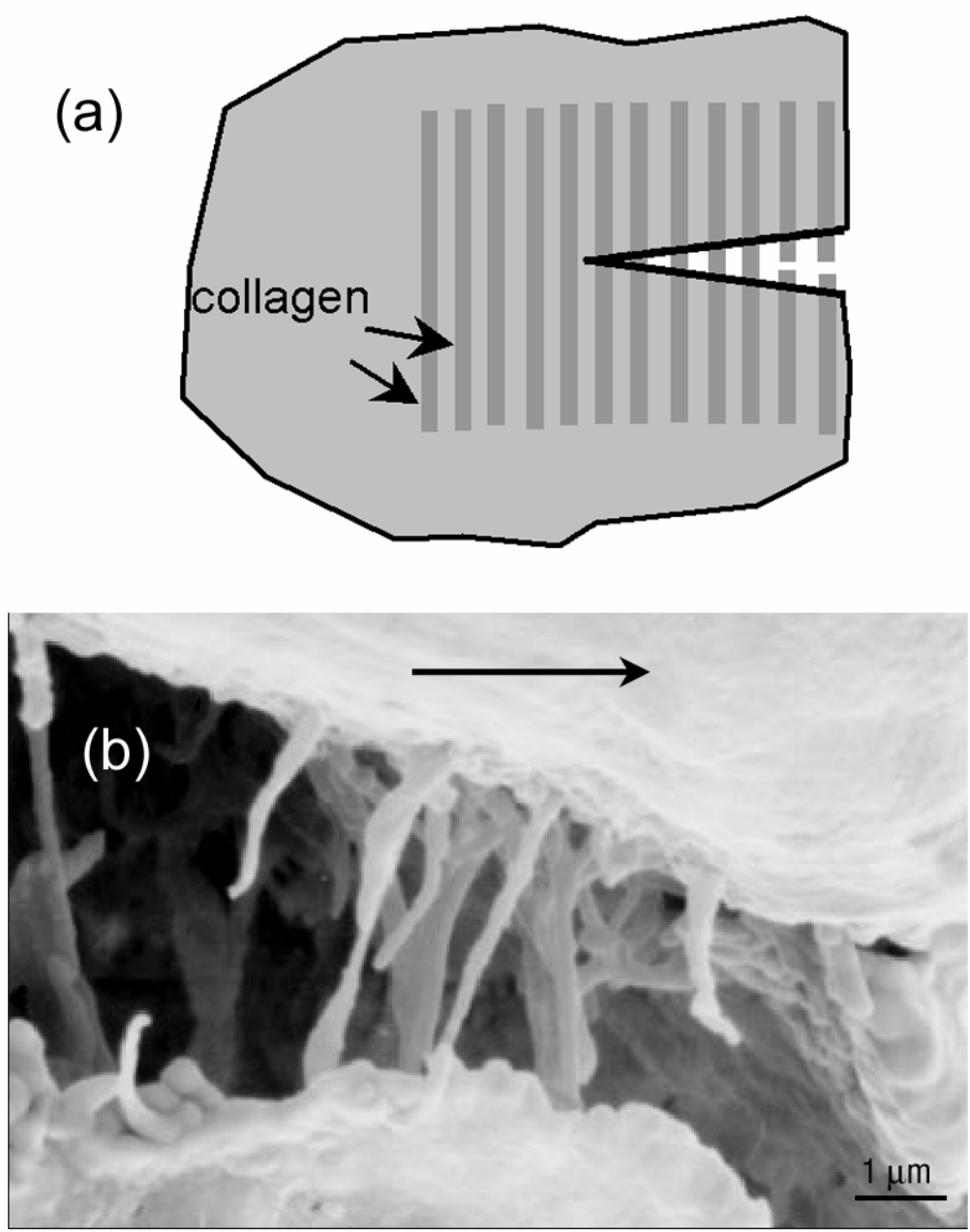

FIG. 4. Collagen fibril bridging is illustrated schematically in (a) and is shown in a scanning electron microscope image of human cortical bone in (b) [30]. The horizontal arrow in (b) indicates the direction of crack growth. 


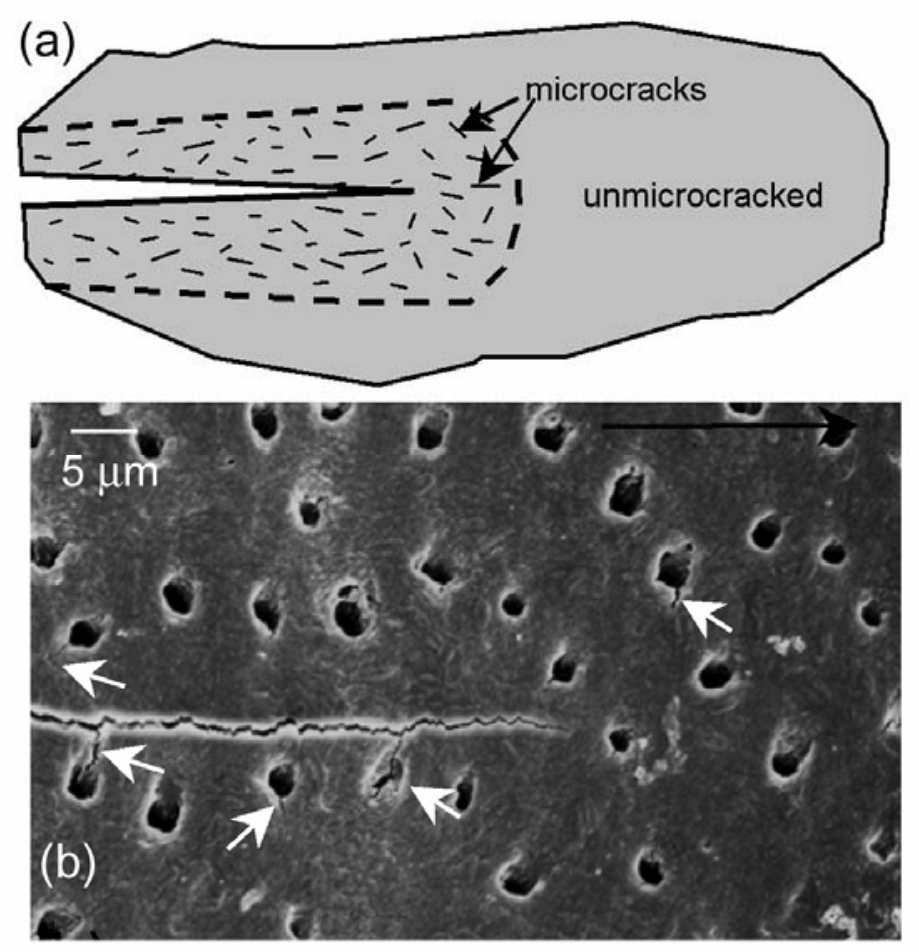

FIG. 5. Microcracking surrounding a larger crack is shown (a) schematically and (b) in a scanning electron microscope image of dentin, a mineralized tissue similar to bone. The horizontal dark arrow in (b) shows the direction of crack growth. Dentin is chosen here to provide a clear representation of the process, which in this case involves the formation of microcracks (white arrows) at the tubules [44]. The structural analysis of microcracks in bone has been reviewed in ref. [39]. 


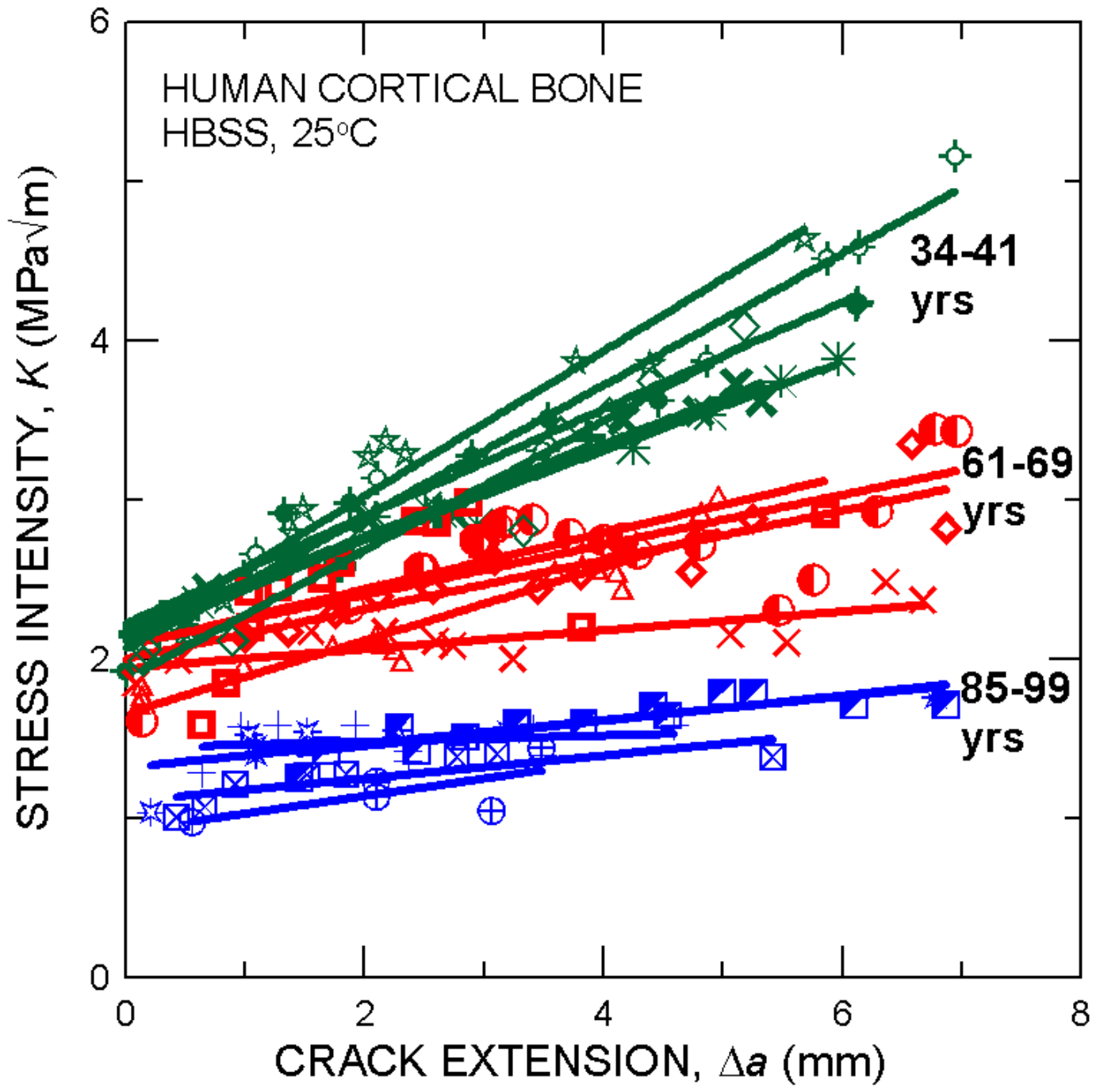

FIG. 6. Crack-resistance curves for stable ex vivo crack extension in human cortical bone as a function of age from 34-41 years to 85-99 years (tested in Hanks' Balanced Salt Solution at $25^{\circ} \mathrm{C}$ ). The crack-initiation toughness, $K_{0}$, is represented by the intercept of the R-curve on the Stress Intensity axis at $\Delta a \rightarrow 0$; the crack-growth toughness is given by the slope of the R-curve [10]. 


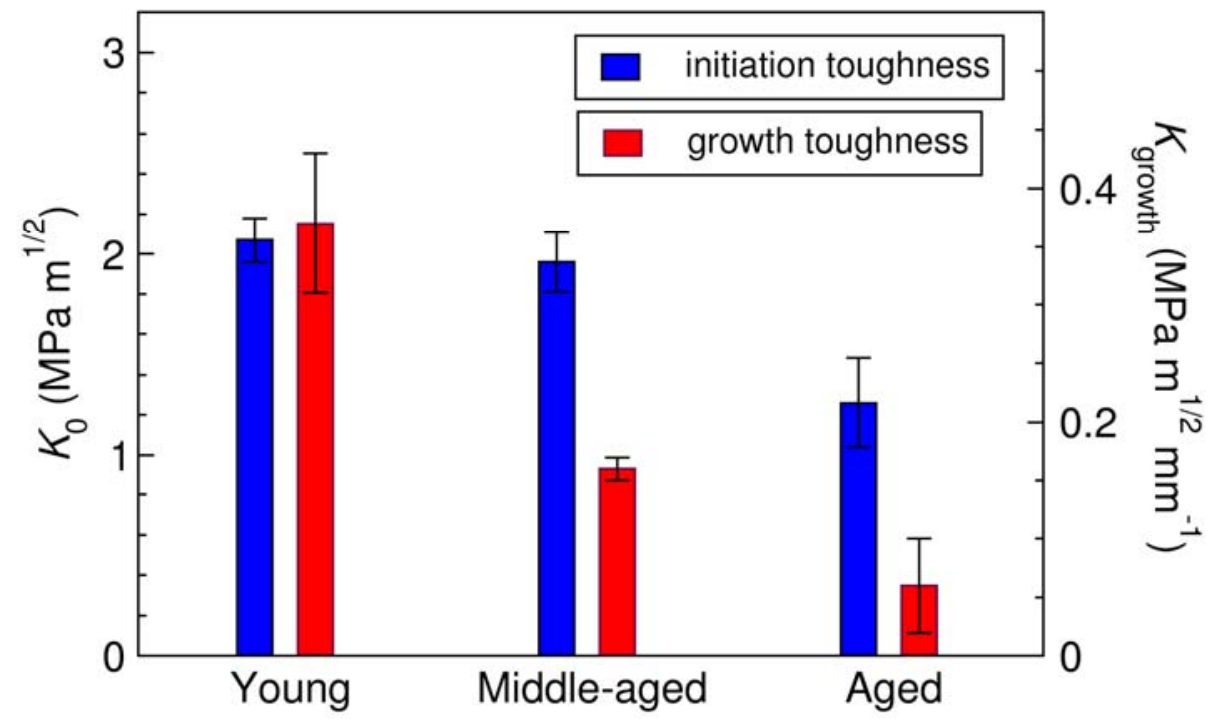

FIG. 7. Variation in crack-initiation toughness (left-hand scale) and crack-growth toughness (right-hand scale) obtained from R-curve measurements on human cortical bone as a function of age (Young $=34-41$ years, Middle-aged $=61-69$ years, Aged $=85$ 99 years). 




FIG. 8. Variation in the (a) crack-initiation toughness, $K_{0}$, and the (b) crack-growth toughness (slope of the R-curve) with osteon density for human cortical bone. The density of (secondary) osteons increases with age. Each data point represents the average for all measurements from one donor. A linear regression of the data is shown in each case (fit equation and coefficient of determination, $\mathrm{R}^{2}$, is also included) [33]. 

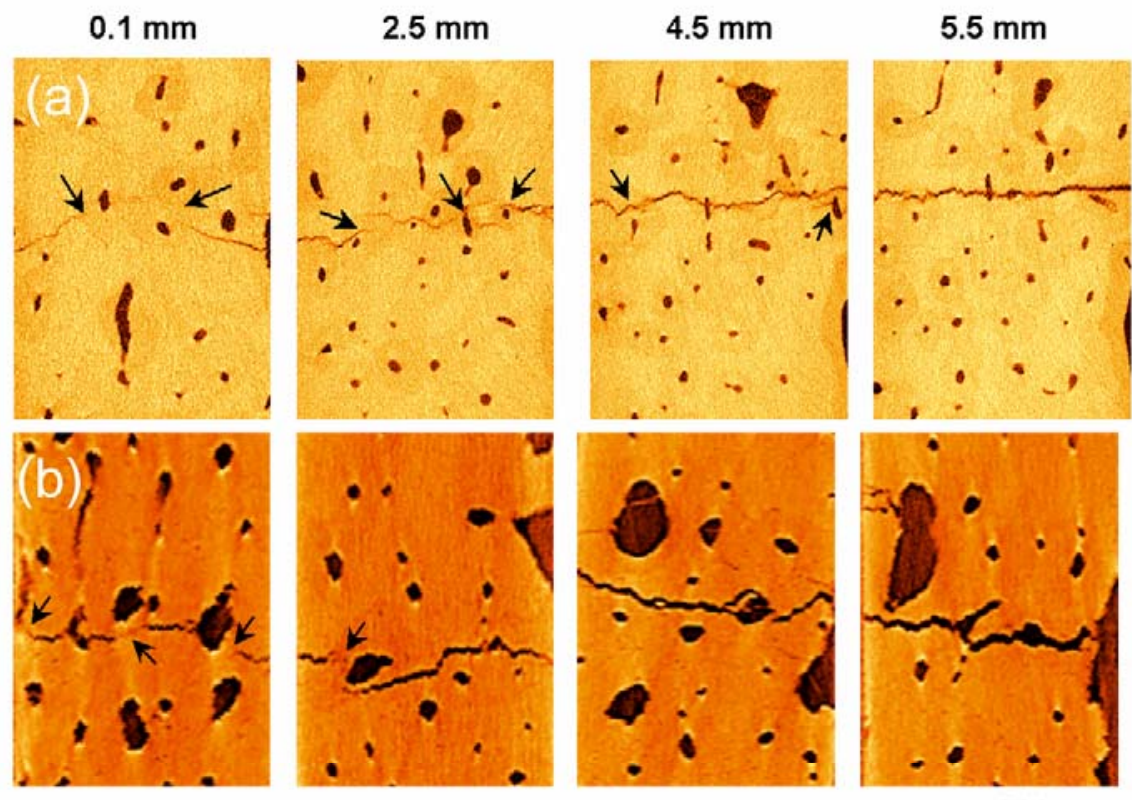

(c)

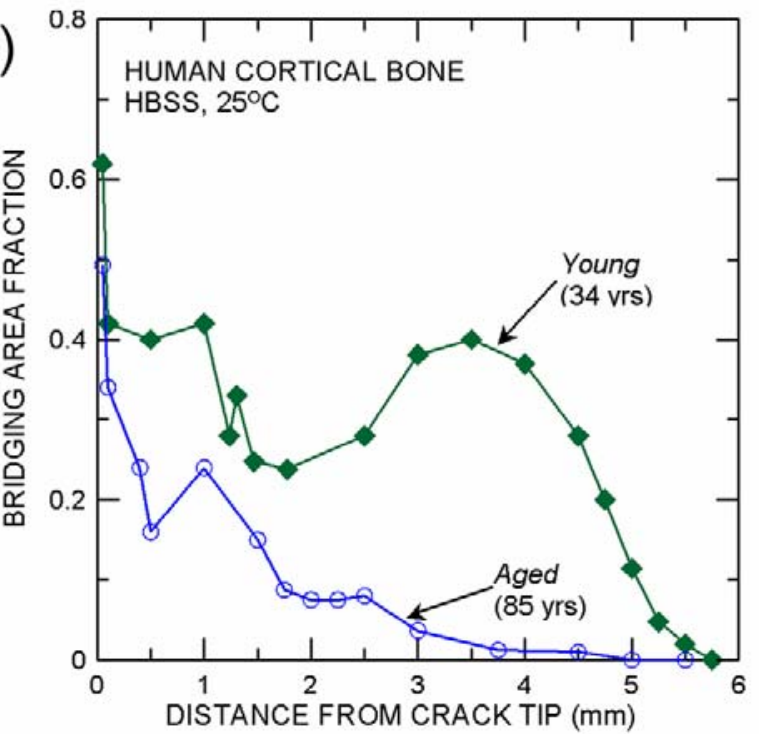

$500 \mu \mathrm{m}$

FIG. 9. Two-dimensional computed $x$-ray tomographic reconstruction slices showing typical cracks in specimens taken from the (a) Young (34 years), and (b) Aged (85 years) human cortical bone groups. The numbers at the top indicate the distance from the (nominal) crack tip, and the black arrows indicate uncracked-ligament "crack bridges". (c) The fraction of such bridges with distance from the crack tip demonstrating the smaller area fractions and bridging-zone size in the older bone [33]. 

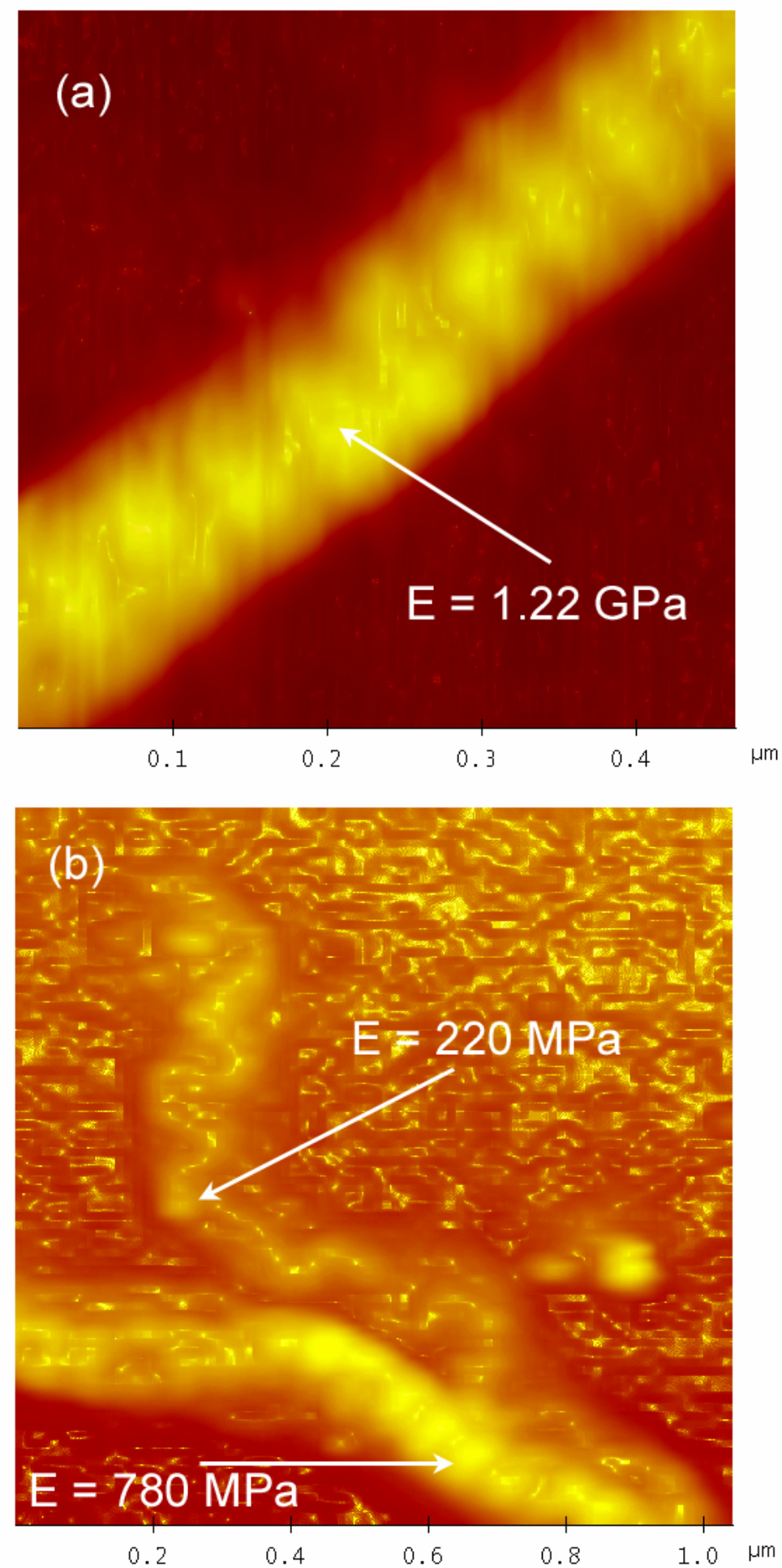

FIG. 10. AFM images with nanoindentation moduli for individual collagen fibrils from samples drawn from the (a) Young (37 years), and (b) Aged (99 years) human cortical bone groups [33]. 
Fracture, Aging and Disease in Bone

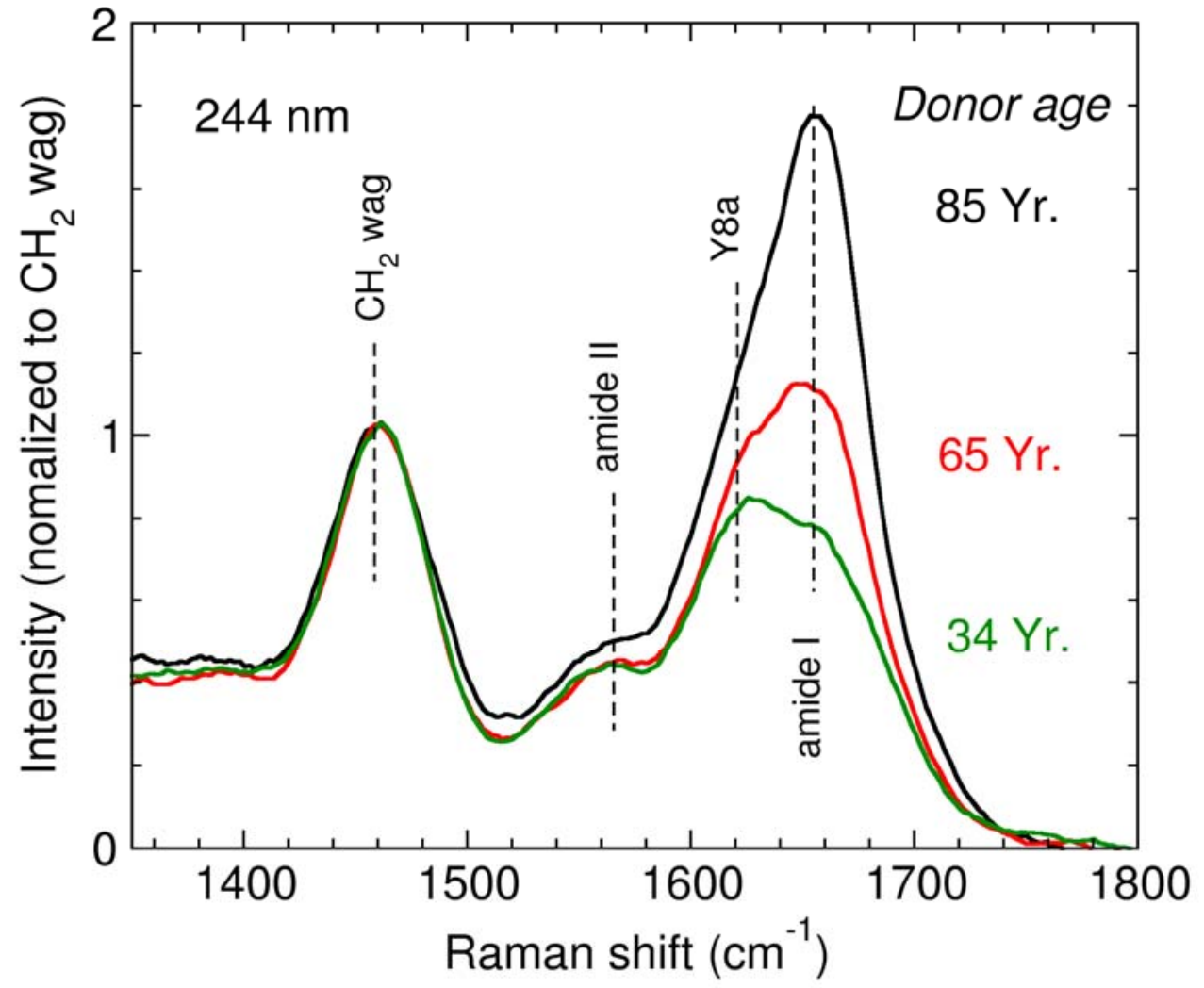

FIG. 11. Deep ultraviolet Raman spectra for human cortical bone from the Young, Middle-Aged, and Aged data sets. Spectral assignments are indicated. The height of the resonance-enhanced amide I feature increases with increasing age 


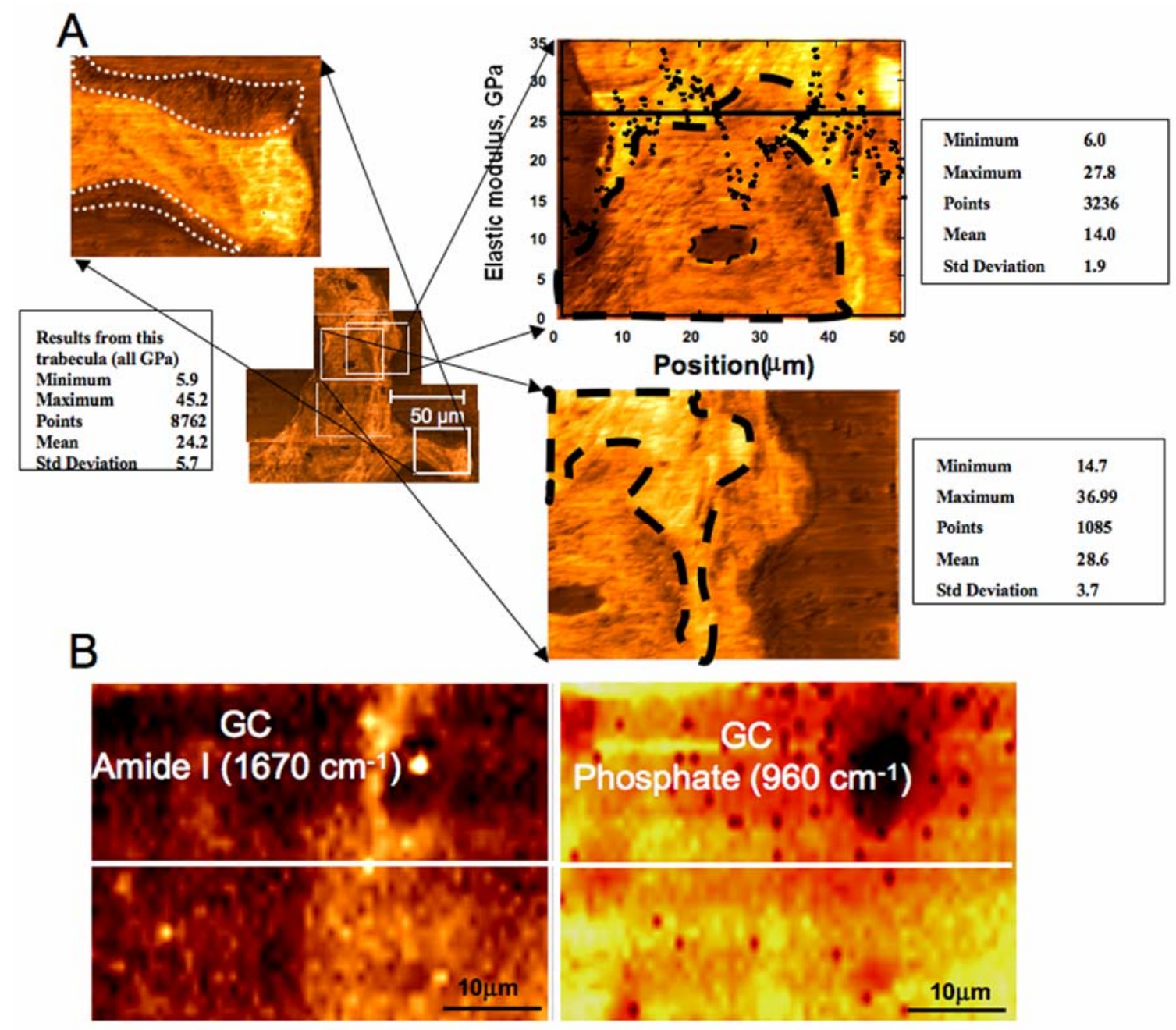

FIG. 12. (a) A representative elastic modulus map from an individual trabecula from glucorticoid (GC) treated mice. The mean elastic modulus is $E=24.2 \pm 1.9 \mathrm{GPa}$. At the remodeling surface, shown in the magnified image at the upper left by white dotted closed-loop lines, a significant reduction in $E$ (30\% below the mean values) was observed. Reductions in $E$ were also observed around the osteocyte lacunae within the trabeculae (shown with black dotted closed-loop lines in the magnified images to the right). (b) Raman micro-spectroscopic imaging of glucocorticoid-treated mouse trabecula. The dark spot in the right hand images indicates a local deficit in the mineral phase and demonstrates that GC treatment reduces the mineralized tissue around the osteocyte lacunae [66]. 


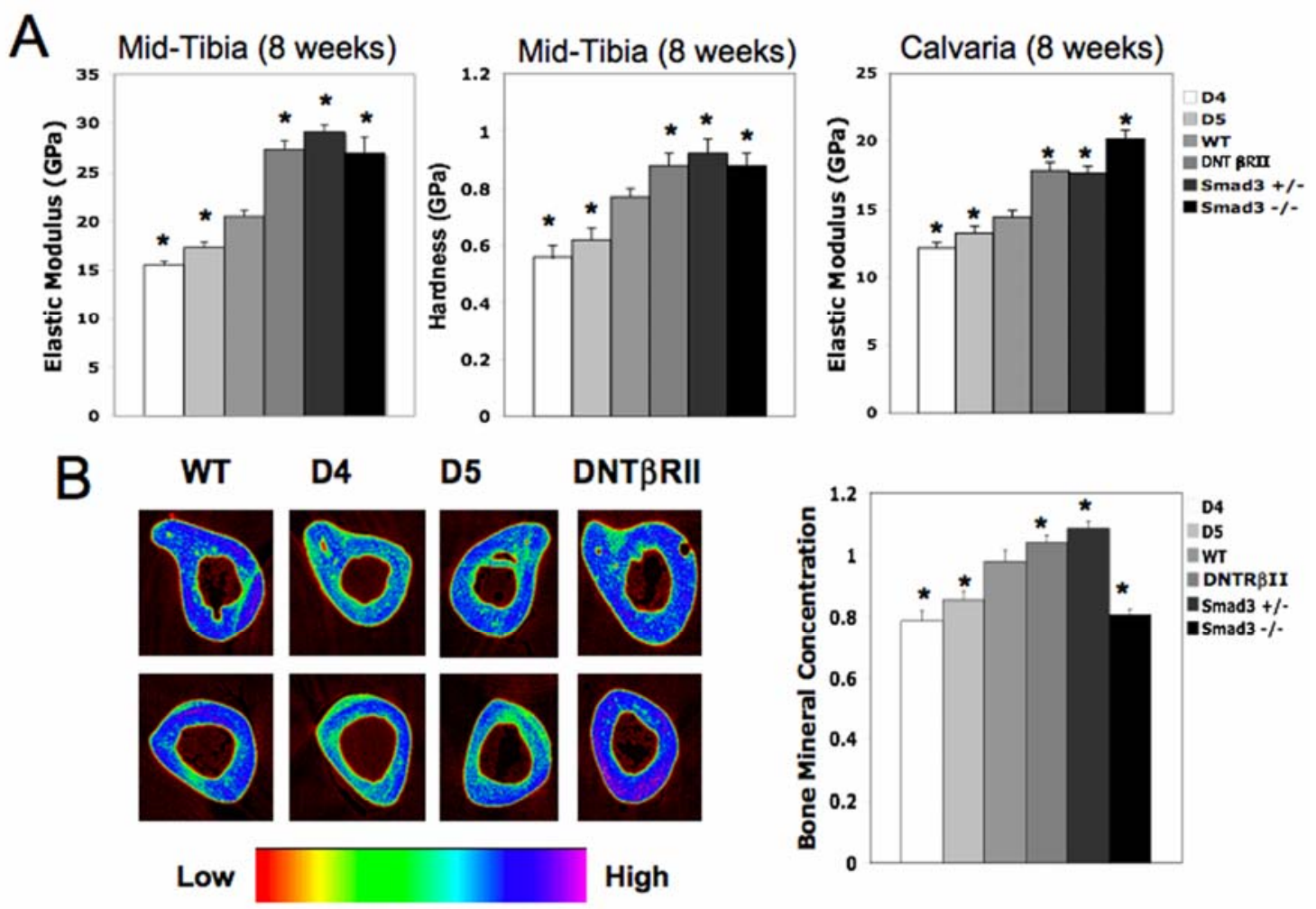

FIG. 13. (a) Individual elastic modulus and hardness values obtained from consecutive nanoindentations in bone in six genotypes of mice with varying levels of TGF- $\beta$. Columns are arranged left to right in order of decreasing TGF- $\beta$ expression. Bones from two month-old animals with elevated TGF- $\beta$ signaling (D4 and D5 mice) had decreased elastic modulus and hardness. Two-month bones with impaired TGF- $\beta$ signaling (DNT $\beta$ RII, Smad3+/-, and Smad3-/- mice) had increased elastic modulus, hardness and fracture toughness. Error bars show standard deviation and stars indicate values that are significantly different from wild-type values $(P<0.001)$. (b) XTM cross sections of two month-old tibia showing effect of TGF- $\beta$ on bone mineral concentration. Quantitative analysis of this data shown demonstrated regulation of mineral concentration by TGF- $\beta$ $(*=P<0.05)[67]$. 